\title{
Facilitation of Pain in the Human Spinal Cord by Nocebo Treatment
}

\author{
Stephan Geuter and Christian Büchel \\ Department of Systems Neuroscience, University Medical Center Hamburg-Eppendorf, 20246 Hamburg, Germany
}

Nocebo hyperalgesia is an increase in subjective pain perception after a patient or subject underwent an inert treatment without any active ingredient. For example, verbal suggestion of increased pain can enhance both pain experience and responses in pain-related cortical brain areas. However, changes in cortical pain responses may be secondary to earlier amplification of incoming pain signals within the spinal cord. To test for a potential early enhancement of pain signals in the dorsal horn of the spinal cord, we combined a nocebo heat pain paradigm with spinal functional magnetic resonance imaging in healthy volunteers. We found that local application of an inert nocebo cream on the forearm increased pain ratings compared with a control cream, and also reduced pain thresholds on the nocebo-treated skin patch. On the neurobiological level, pain stimulation induced a strong activation in the spinal cord at the level of the stimulated dermatomes $\mathrm{C} 5 / \mathrm{C} 6$. Comparing pain stimulation under nocebo to a control pain stimulation of the same physical intensity revealed enhanced pain-related activity in the ipsilateral dorsal horn of the spinal cord. Importantly, the activation of the main effect of pain and the nocebo effect spatially overlapped. The current study thus provides direct evidence for a pain-facilitating mechanism in the human spinal cord before cortical processing, which can be activated by cognitive manipulations such as nocebo treatments.

\section{Introduction}

Although the experience of pain is an important signal to prevent tissue damage, exacerbated pain belongs to the most common maladies of mankind. The individual pain experience can be substantially modulated by many interventions. For example, pain can be reduced by distraction (Valet et al., 2004; Buhle and Wager, 2010; Sprenger et al., 2012), expectation (Koyama et al., 2005; Atlas et al., 2010), or in general by placebo interventions (Levine et al., 1978; Montgomery and Kirsch, 1996; Amanzio and Benedetti, 1999; Benedetti, 2008). On the other hand, pain can be increased by negative expectations, for example in nocebo hyperalgesia (Lorenz et al., 2005; Colloca et al., 2008). In some studies, negative expectations even equalized the effects of analgesic drugs (Dworkin et al., 1983; Bingel et al., 2011). Nocebo-induced hyperalgesia increases pain along with activity in cortical painprocessing areas (Kong et al., 2008; Rodriguez-Raecke et al., 2010). However, the processes leading to increased cortical pain activations are unknown. The amplification of afferent pain signals can occur at several stages along the nociceptive pathways - at cortical areas, in the thalamus, in reticular nuclei, or in

\footnotetext{
Received May 23, 2013; revised July 17, 2013; accepted July 18, 2013.

Author contributions: S.G. and C.B. designed research; S.G. performed research; S.G. and C.B. analyzed data; S.G. and C.B. wrote the paper.

S.G. was supported by the Deutsche Forschungsgemeinschaft, SFB 936, project A06. C.B. was supported by European Research Council Grant ERC-2010-AdG_20100407. We thank Christian Sprenger for help during the scanning; Jürgen Finsterbusch for the development and configuration of the scanning sequences; and Sabrina Boll and G. Elliot Wimmer for helpful comments on an earlier version of this manuscript.

The authors declare no competing financial interests.

Correspondence should be addressed to Stephan Geuter, Department of Systems Neuroscience, University Medical Center Hamburg-Eppendorf, 20246 Hamburg, Germany. E-mail: s.geuter@uke.de.

DOI:10.1523/JNEUROSCI.2191-13.2013

Copyright $\odot 2013$ the authors $\quad 0270-6474 / 13 / 3313784-07 \$ 15.00 / 0$
}

spinal cord. Results implicating subcortical areas in nocebo hyperalgesia (Kong et al., 2008; Scott et al., 2008) hint toward an early modulation of afferent pain signals. Further support for an early modulation comes from a behavioral study, reporting that expectations can modulate the effect of counter-irritation techniques (e.g., immersion of the contralateral arm in cold water) on pain reports and spinal reflexes (Goffaux et al., 2007). While suggestive, these results do not fully demonstrate that the crucial change in nocebo-induced hyperalgesic pain processing depends on a facilitation of incoming pain signals within the spinal cord.

Recent results show that placebo analgesia can reduce pain transmission in the human spinal cord (Eippert et al., 2009b), a finding that is in line with models of spinal control of pain (Basbaum and Fields, 1984; Millan, 2002). However, it has been suggested that placebo and nocebo responses rely on different neurobiological mechanisms (Colloca et al., 2008; Enck et al., 2008; Petrovic, 2008), which could mean that only placebo analgesia affects spinal pain transmission. To test the hypothesis of a spinal cord involvement in nocebo hyperalgesia, we used novel functional magnetic resonance imaging (fMRI) acquisition techniques, allowing for the investigation of pain transmission in the human spinal cord (Eippert et al., 2009b; Cahill and Stroman, 2011; Brooks et al., 2012; Finsterbusch et al., 2012).

The treatment consisted of a local application of basic skin cream on different locations on the left forearm (Fig. 1). Control and nocebo creams were identical except for the labels and did not contain any active ingredient. Using a combination of expectation and experience manipulations (Voudouris et al., 1990; Wager et al., 2004; Colloca et al., 2008), subjects were led to believe that the nocebo cream contained capsaicin, which would enhance heat pain perception. During the fMRI test phase, sub- 
A

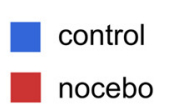

Manipulation phase

\author{
Day 1 - Behavioral test \\ 6 trials each
}

control nocebo

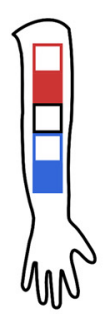

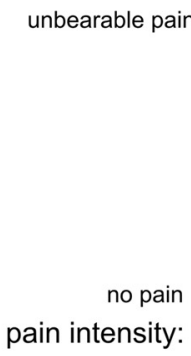

pain intensity:
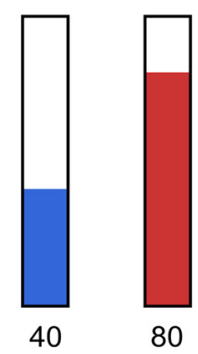

\section{Day 2 - fMRI "off" 6 trials each}

control nocebo
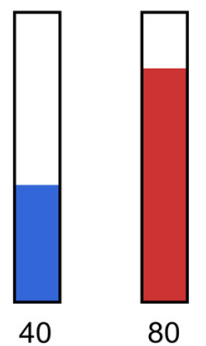

Test phase

Day 2 - fMRI "on" 15 trials each

control nocebo
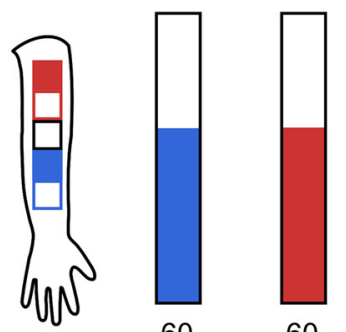

\section{B}

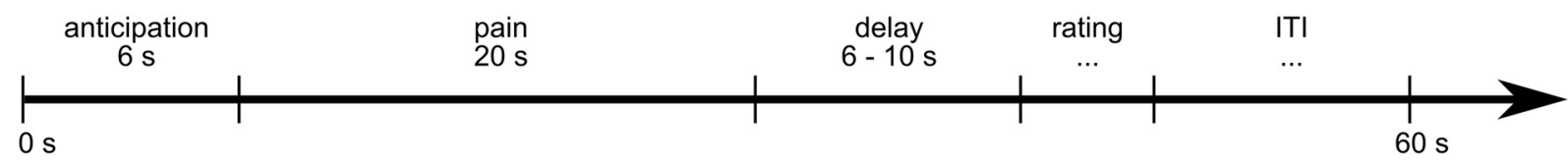

Figure 1. Experimental design. $\boldsymbol{A}$, Four patches on subjects' volar forearm were treated with identical inert creams, but subjects were led to believe that the nocebo cream would increase heat pain perception. Subjects were correctly informed that the control cream did not contain any active ingredient and would thus not affect pain perception. During the manipulation phase, we surreptitiously increased the temperature on the nocebo patch (filled red square on the forearm sketch), thereby simulating an effective treatment. During the fMRI test phase, temperatures were identical. Temperatures were individually calibrated to elicit an average pain rating of 60 on a VAS of $0-100$ during the test phase. Each manipulation session consisted of two blocks of six nocebo trials and six control trials. During the fMRI session, subjects rated 15 painful heat stimuli in each condition. The stimulation order (nocebo first vs control first), and the assignment of conditions to patches (nocebo upper vs control upper) was counterbalanced across subjects. B, During each trial, a fixed anticipation period of $6 \mathrm{~s}$ was followed by $20 \mathrm{~s} \mathrm{heat} \mathrm{pain} \mathrm{stimulation.} \mathrm{After} \mathrm{a} \mathrm{variable} \mathrm{delay}$ of $6-10 \mathrm{~s}$, a VAS rating appeared on the screen and subjects rated the perceived pain intensity of the preceding stimulus. The ITI duration was adjusted in such a way that each trial lasted a total of $60 \mathrm{~s}$.

jects rated the intensity elicited by identical painful heat stimuli at the control and nocebo locations.

\section{Materials and Methods}

Subjects. Twenty-three healthy subjects with no reported history of neurological or psychiatric illnesses, drug abuse, and any skin conditions and/or concurrent medication use participated in this study. Data from three subjects had to be excluded from analysis: during the test of one subject, the physiological monitoring device failed, prohibiting physiological noise modeling (PNM; see below); one subject reported during debriefing that he expected the ointment would be inert on day 2; and one subject described heat pain stimuli as indistinguishable from cold pain. This left 20 subjects ( 8 female subjects; mean age, 26.4 years; age range, $21-40$ years) in the current sample. The Ethics Committee of the Medical Chamber Hamburg approved the study, and all participants gave written consent. All subjects were fully debriefed about the deception after the experiment.

Experimental design. Volunteers were informed that the purpose of the current study was to investigate the effects of capsaicin cream on spinal cord heat pain processing. We explained to the subjects that capsaicin is the active ingredient of chili pepper and that capsaicin treatment leads to local hyperalgesia. Importantly, the creams used in this study were identical in both conditions and did not contain an active ingredient. However, the cream for the nocebo condition was kept in a tube labeled "Hot ThermoDura Capsaicin Cream." The control cream was labeled "Basis Cream (University Hospital)." To investigate the effects of nocebo hyperalgesia, we used a $2 \mathrm{~d}$ paradigm that was similar to previous studies (Voudouris et al., 1989; Wager et al., 2004; Colloca et al., 2008) using both expectation and learning processes. On both days, subjects underwent standard manipulation sessions (Colloca et al., 2008, 2010), and on the second day subjects completed the fMRI test session.

On the first day, subjects arrived at the behavioral laboratory on the campus of the University Medical Center and were greeted by the experimenter wearing a white laboratory coat. First, the aim of the study was explained to the subjects. Then, five squares, $4 \times 4 \mathrm{~cm}$ in size, were drawn on the subjects' left volar forearm to mark stimulation patches on dermatomes C5/C6 (Fig. 1). The two lower patches were used either for nocebo or control, and the two upper patches were used for the remaining condition (counterbalanced across subjects), respectively. One of the two patches per condition was used for manipulation blocks; the other patch was only used during the fMRI test phase to prevent habituation or sensitization effects. The central patch was used for temperature calibration only. After application of nocebo and control creams on two respective patches, the calibration procedure started with an assessment of pain thresholds according to the method of limits with five repetitions (slope $1{ }^{\circ} \mathrm{C} / \mathrm{s}$ ). Pain thresholds were also obtained before each subsequent control and nocebo stimulation series on the respective skin patch. Next, we collected pain ratings for a series of 20 different heat stimuli ( $17 \mathrm{~s}$ plateau duration each) presented in pseudorandom order. Throughout the experiment, subjects rated their perceived pain on a visual analog scale (VAS) with endpoints labeled "no pain" and "unbearable pain." Subjects were instructed to rate unbearable pain only in case they could not tolerate the complete stimulus and had to lift the thermode from their arm (which never happened in this study). Ratings were converted to numerical scores between 0 and 100 for analyses. A sigmoid function was fit to the 20 pain ratings to determine individual temperatures corresponding to VAS scores of 40,60 , and 80 . The mean $( \pm S D)$ temperatures applied in this study were $45.6 \pm 1.1^{\circ} \mathrm{C}$ during the control manipulation, $47 \pm$ $1.0^{\circ} \mathrm{C}$ during nocebo manipulation, and $46.3 \pm 1.0^{\circ} \mathrm{C}$ during the fMRI test phase. After the calibration series, subjects completed a demographic questionnaire, the Pain Catastrophizing Scale (PCS), and the Social Desirability Scale (SDS). Following the questionnaires, a first manipulation session was conducted. Subjects received six heat stimuli on the control and nocebo patches, respectively (Fig. 1). The stimulation order was counterbalanced across subjects. The temperature on the control patch was calibrated to elicit a pain rating of 40 , whereas the temperature on the nocebo patch was calibrated to elicit a pain rating of 80 . Critically, subjects were led to believe that the temperatures were equal and that all 
differences in pain were due to the "capsaicin cream." The session ended with a brief questionnaire regarding the overall painfulness of the heat stimuli on both patches.

On day 2, the experiment took place inside the building housing the MR scanner. Nocebo and control cream were applied to their respective patches, and subjects then waited $10 \mathrm{~min}$ for the creams to take effect. Inside the scanner, a second manipulation session, as on day 1 , was then performed (without acquisition of fMRI data). Subjects then left the scanner, and both creams were applied on the respective test patches. During another break of $10 \mathrm{~min}$, subjects completed the State-Trait Anxiety Inventory (STAI). After returning to the scanner, subjects received 15 heat stimuli in each condition, rating their experienced pain after each stimulus. The temperature was now set to a VAS of 60 and was identical in both conditions. During the test session, we recorded fMRI data of the spinal cord (see Data acquisition), as well as respiration rate and heart rate to correct for physiological noise in the fMRI data (Brooks et al., 2008; Kong et al., 2012). Finally, subjects left the MRI scanner, completed the questionnaire regarding experienced pain a second time, and were debriefed.

Each trial during manipulation and test sessions consisted of an anticipation phase $(6 \mathrm{~s})$, heat stimulation (20 s: $1.5 \mathrm{~s}$ ramp-up, $1.5 \mathrm{~s}$ rampdown, and $17 \mathrm{~s}$ plateau), a variable delay $(7-10 \mathrm{~s})$, pain rating and intertrial interval (ITI; Fig. 1). The rating duration depended on the subject's actions in each trial, and the ITI duration was automatically adjusted so that each trial lasted $60 \mathrm{~s}$ in total.

Data acquisition. We used Matlab (version 7.12, MathWorks) and Cogent 2000 (version 1.32, http://www.vislab.ucl.ac.uk/cogent.php) for stimulus presentation, response logging, and synchronization with the physiological data. Thermal stimulation was delivered by a TSA II (Medoc) with a $3 \times 3 \mathrm{~cm}$ thermode head surface. Respiration and heart rate (i.e., pulse oximetry) were recorded using an Expression system (Saegeling). Physiological signals were digitized at $1000 \mathrm{~Hz}$ using a CED 1401 micro3 and Spike2 software (both by Cambridge Electronic Design).

Subjects were carefully positioned inside the MR scanner; vacuum cushions were used to stabilize slim subjects as much as possible without being inconvenient for them. The target region at spinal segments C5/C6 was positioned in the isocenter of the magnet. A high-resolution MPRAGE image $(1 \times 1 \times 1 \mathrm{~mm}$; matrix size, $192 \times 240 \times 256$; $\mathrm{TR}=$ $2.3 \mathrm{~s}$; TE $=3.43 \mathrm{~ms}$; flip angle $=9^{\circ}$ ) covering the CNS from the body of the corpus callosum down to the second thoracic vertebra was acquired before the functional runs. The structural image was acquired using a 12-channel head coil and a 4-channel neck coil. Only the neck coil was used for acquisition of the functional images. A gradient-echo echoplanar imaging sequence was used to measure functional T2*-weighted images (voxel size, $1 \times 1 \times 5 \mathrm{~mm}$; matrix size, $128 \times 128 \times 10$; $\mathrm{TR}=1170$ $\mathrm{ms}$; $\mathrm{TE}=42 \mathrm{~ms}$; flip angle $=70^{\circ}$; GRAPPA with parallel acquisition technique factor 2) during the test phase. The stack of axial slices was centered on the fourth intervertebral disc covering the spinal cord from the lower portion of the fourth vertebra to the upper part of the seventh vertebra. Spatially selective saturation bands were applied superior and inferior to the field of view, and flow rephasing in the slice direction was used to minimize noise from flow effects. Additional saturation bands were applied anterior and posterior to our target region in the spine to minimize pulsatile blood inflow artifacts. To reduce signal intensity variations along the cord caused by magnetic field inhomogeneity due to different magnetic susceptibilities of the vertebral bodies and intervertebral discs (Cooke et al., 2004), we used slice-specific gradient pulses (Finsterbusch et al., 2012). These slice-specific gradient moments were determined from a reference scan with 21 different gradient moments applied to each slice. The specific gradient moment yielding the maximal signal intensity was selected for each slice. Since spinal cord fMRI data suffer from cardiac and respiratory artifacts, we recorded heart rate and respiration to retrospectively correct for these effects (Glover et al., 2000; Brooks et al., 2008; Piché et al., 2009).

Behavioral data analyses. Behavioral data were analyzed using Matlab (version 7.11). Pain thresholds were calculated as the mean temperature of the last three repetitions on each skin patch. The two initial temperature ramp-ups were excluded, because they are less reliable than the following repetitions. Nocebo effects were tested by comparing mean pain ratings and pain thresholds for control to nocebo conditions during the fMRI test phase using paired $t$ tests. To test for linear trends in the difference between nocebo and control, the pain rating difference was regressed onto the trial number (i.e., 1-15). Questionnaire scores (i.e., STAI, SDS, and PCS) were correlated with the pain rating and pain threshold difference scores using Pearson's correlation. For all behavioral analyses, a Bonferroni corrected significance threshold of $p<0.05$ (onetailed in case of a priori hypotheses) was used. As we used a withinsubject design, the normal SEM does not reflect statistical differences between conditions because it is heavily affected by between-subject variability. We therefore corrected the error bars according to the method proposed by Loftus and Masson (1994) without calculating analyses of variance (Franz and Loftus, 2012).

fMRI data analyses. Imaging data were preprocessed and analyzed using SPM8 (Wellcome Trust Centre for Neuroimaging, London, UK). Motion correction was performed using the SPM standard six-parameter rigid-body transformation procedure. To reduce the influence of muscle and CSF variations (Stroman et al., 1999), images were automatically masked to include only the spinal cord and surrounding tissue (Eippert et al., 2009b). From this mask, regions with high temporal variance (i.e., CSF) were excluded. Masks were specifically created for each subject. Each subject's anatomical image was then semimanually coregistered to the respective mean functional image using a six-parameter rigid-body transformation. Since structural and functional images were acquired in close temporal succession and subjects were instructed not to move, the initial overlap was already high.

Spatially normalization for group analyses proceeded in the following steps. First, the origin of all images was reset to the ventral border of the spinal cord at the level of the fourth intervertebral disc. The origin was thereby placed on a reliably detectable landmark close to our area of interest. Second, we then averaged the anatomical images and normalized the image of one subject with the least curved spine onto the average anatomical image. This resulted in our group template image, which has the average spinal curvature in our area of interest. Third, anatomical images were normalized to the previously created group template image using both affine and nonlinear transformations. The latter were constrained by discrete cosine basis functions on the order of $22 \mathrm{~mm}$ (in $x, y$, and $z$ directions). To normalize the spinal cord as accurately as possible, the template image was masked with 2D Gaussians in axial planes, centered on the spinal cord. The full-width at half-maximum (FWHM) of the isotropic 2D Gaussians was individually set for each subject within a range of 3-5 mm. Fourth, the normalization parameters obtained from the anatomical images were then applied to the coregistered functional images, and functional images were resampled to a resolution of $1 \times 1 \times$ $1 \mathrm{~mm}$. Finally, functional images were smoothed using a 3D isotropic Gaussian kernel with an FWHM of $3 \mathrm{~mm}$.

For the fMRI data, anticipation and pain periods were modeled as separate boxcar regressors. Each button press during the pain rating was modeled as a delta function. All regressors were convolved with a canonical hemodynamic response function. These three regressors plus session constants were defined for both fMRI runs. To model noise arising from cardiac and respiratory fluctuations (Brooks et al., 2008), we used physiological noise modeling (Brooks et al., 2008, 2012), which is based on the RETROICOR method (Glover et al., 2000). Briefly, PNM uses a Fourier series to model physiological measures (here, respiration and heart rate). The phase of the cardiac cycle is determined from the pulse oximeter recording relative to the fMRI volume acquisition. A histogramequalized transfer function (Glover et al., 2000) was used to determine the respiratory phase. We modeled physiological noise frequencies up to and including the third harmonic of the respiratory (and pulse) principal frequency using sine and cosine functions. An additional 16 nuisance regressors representing multiplicative interactions of the heart rate and respiratory cycle for sine and cosine terms were included for a total of 32 PNM regressors per run (Kong et al., 2012). To remove low-frequency fluctuations caused by CSF pulsations, we also included a regressor modeling the mean CSF signal as determined from the most variable quartile of voxels (Eippert et al., 2009b; Kong et al., 2012). Furthermore, six motion parameters estimated during realignment were included, resulting in 39 nuisance regressors per functional run. Data were high-pass 


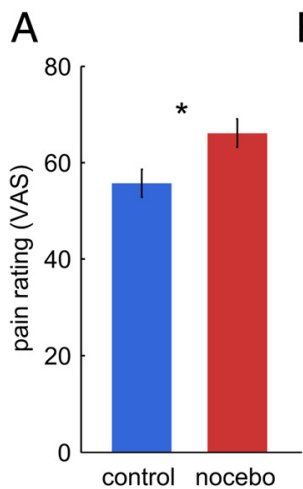

B

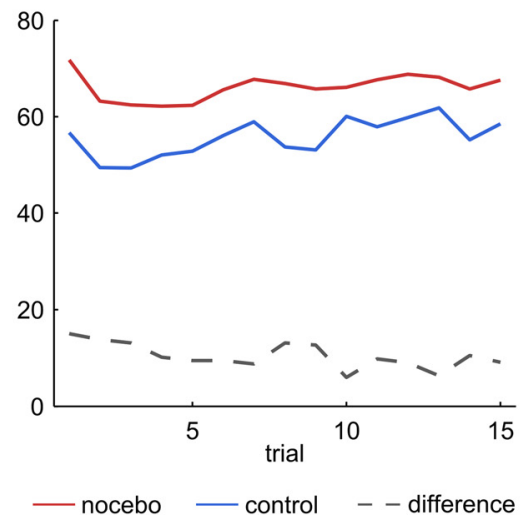

Figure 2. Behavioral results. $A$, Subjects perceived heat stimuli on the nocebo patch as more painful than on the control patch $\left(t_{(19)}=2.54 ; p=0.02\right)$. B, Pain ratings over trials were stable, but the nocebo effect (dashed line) decreased slightly over time $\left(b=-0.36 ; t_{(13)}=2.83 ; p=0.01\right)$. C, Pain thresholds obtained immediately before the test stimulation inside the fMRI scanner were lower on the nocebo patch than on the control patch $\left(t_{(19)}=2.61 ; p=0.017\right)$, indicating increased thermal sensitivity due to nocebo treatment. *Indicates a significant difference at $p<0.05$. Error bars represent SEM after correction for between-subject variability (see Behavioral analyses).

filtered at a cutoff period of $128 \mathrm{~s}$ and were corrected for serial autocorrelations using a first-order autoregressive model. After single-subject model estimation, we raised the $\beta$-images for pain stimulation to a group-level random-effects analysis. We evaluated the following secondlevel contrasts: main effect of pain (control plus nocebo; nocebo $>$ control; and control $>$ nocebo). As the number of voxels in our dataset was small and the a priori hypothesis was clearly specified for the ipsilateral dorsal horn, we used a statistical threshold of $p<0.005$, uncorrected. In addition to the voxelwise results, we conducted a region of interest (ROI) analysis. We manually constructed a mask on the anatomical group mean image covering the left dorsal quadrant of the C5/C6 segment. Parameter estimates were extracted for pain control and pain nocebo using this mask. These estimates were then averaged across voxels within each subject and compared using a paired $t$ test. Evoked responses due to painful stimulation were extracted at the peak voxel of the nocebo effect using the rfxplot toolbox (http://rfxplot.sourceforge.net/; Gläscher, 2009). To compare the effect sizes (ESs) of spinal and behavioral responses, we calculated corrected ESs (Gibbons et al., 1993). Behavioral effect size was calculated from pain ratings. For the spinal effect size, we used extracted parameter estimates, as described for the ROI analysis. Furthermore, we used the mean difference of the extracted parameter estimates as a measure for the spinal nocebo response and correlated that with the behavioral nocebo effect. Please note that the mask was defined using the mean anatomical image and is independent of our statistical maps.

One alternative explanation for any effect of nocebo $>$ control in the spinal cord may be that stimuli perceived as more painful might induce stronger muscle contraction and thereby lead to spinal activations. As a proxy for subject movement, we compared the average volume-tovolume motion as estimated during the realignment of the functional images. The volume-to-volume difference of each of the six rigid-body transformation parameters $(x-, y$-, and $z$-translation, pitch, roll, and yaw) was compared between nocebo and control using paired $t$ tests (multivariate ANOVA is not appropriate here because of the highly correlated dependent variables). Even uncorrected $p$ values were not significant (all $p$ values $>0.07$; all $t$ values $<2$ ). Volume-to-volume motion was also greater in the control condition, except for $y$-translation and pitch.

\section{Results}

Behavioral results

The first analysis compared behavioral pain ratings obtained from 20 subjects between nocebo and control conditions. Nocebo treatment significantly increased pain ratings compared
C with control $\left(t_{(19)}=2.54 ; p=0.01\right.$; Fig.

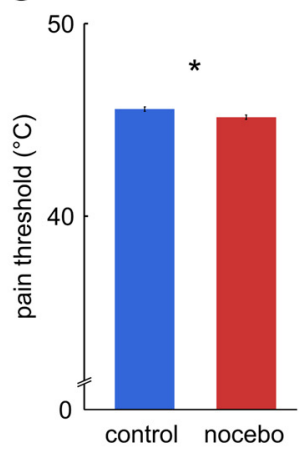

$2 A)$ from a mean $( \pm S D)$ of $55.7 \pm 21.2$ to $66.1 \pm 20.5$ on a scale ranging from 0 to 100. Linear regression analysis revealed a small but significant decrease in the nocebo - control difference over trials $(b=$ $-0.36 ; t_{(13)}=2.83 ; p=0.014$; Fig. $2 B$ ). Further, temperatures corresponding to the individual pain thresholds obtained directly before each test were lower on the nocebo patch compared with the control treatment patch $\left(t_{(19)}=2.61 ; p=0.008\right.$; Fig. $2 C$ ). The mean pain threshold on the control patch was $45.3 \pm 1.6^{\circ} \mathrm{C}$, and on the nocebo patch, $44.1 \pm 2.6^{\circ} \mathrm{C}$. Hence, subjects experienced lower temperatures as painful and perceived identical stimuli as more painful following nocebo treatment. We also obtained questionnaire scores for psychological constructs potentially moderating nocebo responses using the PCS, the STAI, and the SDS. None of the questionnaire scores correlated with the nocebo response (i.e., the difference in nocebo - control) in pain ratings or pain thresholds (all $r<0.32$; all $p>0.18$ ).

\section{fMRI results}

To assess the general effects of pain stimulation within the spinal cord, we first tested for a main effect of pain during heat stimulation periods in both conditions. In the spinal cord, this revealed a strong blood oxygenation level-dependent (BOLD) effect of pain at the level of C5 and C6 (Fig. 3A) spanning the whole fifth vertebrate body. The location of the pain cluster at level C5/C6 is in accordance with the stimulated area on the volar forearm. The pain cluster extended across the whole axial cord section, and its peak was located in the center of the ipsilateral left hemicord, an area corresponding to the deep laminae and intermediate zone $\left(t_{(19)}=11.46 ; p<0.001\right)$. For the critical comparison, we next tested for increased pain signals under nocebo by evaluating the contrast (nocebo $>$ control). In a region inclusively masked with the main effect of pain at $p<0.005$, this contrast revealed a cluster in the ipsilateral dorsal horn (Fig. $3 C$; $t_{(19)}=3.26 ; p=$ 0.002). Importantly, these two peaks were in close spatial proximity. The time course of the estimated response to painful stimulation is plotted in Figure 4. The signal increased earlier when a nocebo treatment was applied compared with control.

No significant voxels were observed for the reverse contrast (control $>$ nocebo). An ROI analysis revealed similar results as the voxelwise analysis. Parameter estimates for the pain stimulation, extracted from the left dorsal quadrant of the spinal cord, were higher for nocebo compared with control (Fig. $3 B ; t_{(19)}=$ 2.32; $p=0.016)$.

To compare the magnitude of behavioral and spinal responses, we computed effect sizes and compared them. The estimated effect size for the pain ratings was $\mathrm{ES}=0.56$, and for the spinal signal, ES $=0.49$, which is $88 \%$ of the behavioral ES. However, the correlation between the spinal-nocebo effect and the behavioral nocebo effect was nonsignificant $(r=0.18 ; p=0.45)$.

\section{Discussion}

Our results show that nocebo manipulation led to increased pain perception, lowered pain thresholds, and increased the BOLD signal in the ipsilateral dorsal horn of the spinal cord. The current 
study thus provides direct evidence for an early pain-facilitating mechanism acting in humans at the spinal level.

As the nocebo and control pain stimulation was equal, top-down processes must have modulated the spinal BOLD signals during pain stimulation. These top-down modulations were induced by the psychosocial context during the study and through the subjects' prior experience. The location of the noceboenhanced pain signal within the ipsilateral dorsal horn, its overlap with the main effect of pain, and the close proximity of the respective peaks demonstrate noceboinduced increases in spinal pain signals. While our spinal fMRI procedure gives high in-plane resolution, the spatial resolution of fMRI is nevertheless limited. Therefore, we cannot disentangle presynaptic and postsynaptic processes within the dorsal horn. However, based on animal studies, it is likely that the painfacilitating circuit involves both spinal and supraspinal neuronal populations. Animal studies have demonstrated pronociceptive neuronal circuits originating in the rostroventral medulla (RVM) and targeting the spinal cord (Kovelowski et al., 2000; Marshall et al., 2012). Within the RVM, two distinct cell types modulate spinal nociceptive signals_ on cells and off cells (Fields, 2004). Tonic activation of off cells is thought to inhibit nociceptive signals in the dorsal horn, whereas activation of on cells supports hyperalgesic states (Urban and Gebhart, 1999; Fields, 2004; Neubert et al., 2004). Since the RVM can be activated by psychosocial manipulations (e.g., placebo analgesia) in humans (Eippert et al., 2009a), and given its bidirectional control of pain modulation (Fields, 2004), it is probably also engaged in nocebo hyperalgesia. This could be mediated either through selective on-cell activation or through the inhibition of off cells. A direct test of this hypothesis would be the application of a nocebo treatment, and concurrent imaging of the RVM and spinal cord in humans. Given recent advances in combined spino-cortical imaging (Finsterbusch et al., 2013), it will soon become possible to investigate both structures simultaneously and noninvasively. Using this novel technique, the direct investigation of descending pain control systems will be possible.

An important question is to what degree spinal and supraspinal processes contribute to the behavioral hyperalgesia. Since the estimated effect sizes were comparable in magnitude, one could argue that the behavioral hyperalgesia is almost entirely due to spinal amplification of nociceptive signals. However, the low correlation between spinal and behavioral nocebo responses suggests a more complex mechanism. This can be due to nonlinear relationships, for example in the neurovascular coupling. As the activation of pro-nociceptive and anti-nociceptive circuits can be dependent on sex (Mogil et al., 2011), interactions with sex or 0.005 .
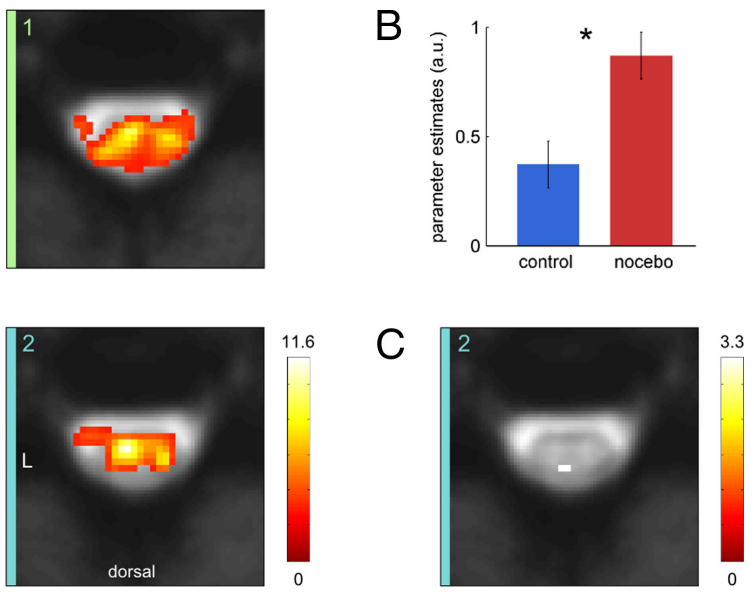

Figure 3. $\mathrm{fMRI}$ results. $\boldsymbol{A}$, Main effect of painful stimulation overlaid on a sagittal slice of the averaged T1-weighted images and axial sections of the mean functional image. One contiguous pain cluster at the level of $C 5 / C 6$ was observed at the set threshold of $p<0.005$. Peak location was in the left ipsilateral hemicord on the axial section 2. B, Parameter estimates for the pain stimulation compared with control $\left(t_{(19)}=2.32 ; p=0.016\right)$. * Indicates a significant difference at $p<0.05$. Error bars represent SEM after correction for between-subject variability (see Behavioral analyses). $\boldsymbol{C}$, The contrast (nocebo $>$ control) masked with the main effect of pain revealed a nocebo-induced signal increase in the left ipsilateral dorsal horn. Statistical $t$ maps are thresholded at $p<$

Figure 4. Time course of the spinal response to pain. Parameter estimates were extracted for both conditions at the peak voxel of the nocebo $>$ control contrast. The shaded area indicates the SEM, and the gray line marks the time of heat stimulation.

personality traits could also be involved here (Whalley et al., 2008). Hence, the observed amplification of pain signals in the spinal cord suggests a key role for spinal modulatory processes in nocebo hyperalgesia but does not exclude further modulations of pain responses at later, cortical, areas.

Expectations can also modulate the efficacy of pain inhibition by counter-irritation techniques, such as immersion of the contralateral arm in cold water (Goffaux et al., 2007). Behaviorally, it has been reported that the induction of analgesia or hyperalgesia expectation, respectively, affects the modulation of spinal reflexes by other treatments. These results demonstrate the behavioral relevance of expectation-based top-down modulation of spinal processes. In line with these findings (Goffaux et al., 2007), our results demonstrate that nocebo hyperalgesia is directly reflected in spinal pain signals.

The thermal pain stimulation produced a very robust and widespread activation spanning the whole level of the fifth vertebrate body. The great strength and extent of the pain-related 
activation was probably due to the combination of the relatively large sample size compared with other spinal fMRI studies, use of slice-specific gradient offsets (Finsterbusch et al., 2012), and the novel spinal normalization procedure (see Materials and Methods). The peak activation was at the same rostral-caudal level as in previous studies using a similar pain stimulation protocol (Eippert et al., 2009b; Sprenger et al., 2012), supporting the reliability of spinal fMRI in detecting pain activation. The spinal response to pain stimulation was bilateral, as in other previous spinal fMRI studies (Summers et al., 2010; Brooks et al., 2012). As expected, the peak of the pain response was clearly ipsilateral to the stimulation side, at the border of the dorsal horn and the intermediate column. Another lower peak was located on the contralateral side, but the cluster was continuous across both sides at the set threshold. Such bilateral responses may reflect contralateral projections (Light and Perl, 1979) or spinal interneuron activity, which has recently been involved in pain processing (Sotgiu et al., 2004; Wang et al., 2013).

An alternative explanation of the observed BOLD signal increases in the nocebo condition might be that subjects contracted their muscles more when they experienced more pain under nocebo. The observed activation could then be attributed to increased motor signals in the spinal cord. Although we cannot completely rule out this hypothesis, we think that the origin of the observed signal is more likely to be related to an amplification of sensory signals. First, we did not find any difference between the motion parameters of the two conditions. Second, withdrawal behavior would also involve other muscle groups controlled by different spinal segments. The observed activation was, however, clearly localized at the expected level within the pain effect.

In summary, the observed nocebo amplification of spinal pain signals demonstrates a cognitive facilitation of pain processing in humans at the first relay of incoming nociceptive signals. When expectations increase pain signals before cortical processing, the subjective pain experience may rely on exaggerated pain information, making it harder to ignore the pain. People, who constantly expect some action to be painful, will experience this action as more painful due to increased pain signals. This in turn, will strengthen the pain-enhancing expectations. In case such pain-exaggerating thoughts are maintained over a long time, these may eventually support the chronification of pain.

\section{References}

Amanzio M, Benedetti F (1999) Neuropharmacological dissection of placebo analgesia: expectation-activated opioid systems versus conditioningactivated specific subsystems. J Neurosci 19:484-494. Medline

Atlas LY, Bolger N, Lindquist MA, Wager TD (2010) Brain mediators of predictive cue effects on perceived pain. J Neurosci 30:12964-12977. CrossRef Medline

Basbaum AI, Fields HL (1984) Endogenous pain control systems: brainstem spinal pathways and endorphin circuitry. Annu Rev Neurosci 7:309-338. CrossRef Medline

Benedetti F (2008) Mechanisms of placebo and placebo-related effects across diseases and treatments. Annu Rev Pharmacol Toxicol 48:33-60. CrossRef Medline

Bingel U, Wanigasekera V, Wiech K, Ni Mhuircheartaigh R, Lee MC, Ploner M, Tracey I (2011) The effect of treatment expectation on drug efficacy: imaging the analgesic benefit of the opioid remifentanil. Sci Transl Med 3:70ra14. CrossRef Medline

Brooks JC, Beckmann CF, Miller KL, Wise RG, Porro CA, Tracey I, Jenkinson M (2008) Physiological noise modelling for spinal functional magnetic resonance imaging studies. Neuroimage 39:680-692. CrossRef Medline

Brooks JC, Kong Y, Lee MC, Warnaby CE, Wanigasekera V, Jenkinson M, Tracey I (2012) Stimulus site and modality dependence of functional activity within the human spinal cord. J Neurosci 32:6231-6239. CrossRef Medline
Buhle J, Wager TD (2010) Performance-dependent inhibition of pain by an executive working memory task. Pain 149:19-26. CrossRef Medline

Cahill CM, Stroman PW (2011) Mapping of neural activity produced by thermal pain in the healthy human spinal cord and brain stem: a functional magnetic resonance imaging study. Magn Reson Imaging 29:342352. CrossRef Medline

Colloca L, Sigaudo M, Benedetti F (2008) The role of learning in nocebo and placebo effects. Pain 136:211-218. CrossRef Medline

Colloca L, Petrovic P, Wager TD, Ingvar M, Benedetti F (2010) How the number of learning trials affects placebo and nocebo responses. Pain 151: 430-439. CrossRef Medline

Cooke FJ, Blamire AM, Manners DN, Styles P, Rajagopalan B (2004) Quantitative proton magnetic resonance spectroscopy of the cervical spinal cord. Magn Reson Med 51:1122-1128. CrossRef Medline

Dworkin SF, Chen AC, LeResche L, Clark DW (1983) Cognitive reversal of expected nitrous oxide analgesia for acute pain. Anesth Analg 62:10731077. Medline

Eippert F, Bingel U, Schoell ED, Yacubian J, Klinger R, Lorenz J, Büchel C (2009a) Activation of the opioidergic descending pain control system underlies placebo analgesia. Neuron 63:533-543. CrossRef Medline

Eippert F, Finsterbusch J, Bingel U, Büchel C (2009b) Direct evidence for spinal cord involvement in placebo analgesia. Science 326:404. CrossRef Medline

Enck P, Benedetti F, Schedlowski M (2008) New insights into the placebo and nocebo responses. Neuron 59:195-206. CrossRef Medline

Fields H (2004) State-dependent opioid control of pain. Nat Rev Neurosci 5:565-575. CrossRef Medline

Finsterbusch J, Eippert F, Büchel C (2012) Single, slice-specific z-shim gradient pulses improve $\mathrm{T} 2^{\star}$-weighted imaging of the spinal cord. Neuroimage 59:2307-2315. CrossRef Medline

Finsterbusch J, Sprenger C, Büchel C (2013) Combined T2*-weighted measurements of the human brain and cervical spinal cord with a dynamic shim update. Neuroimage 79:153-161. CrossRef Medline

Franz VH, Loftus GR (2012) Standard errors and confidence intervals in within-subjects designs: generalizing Loftus and Masson (1994) and avoiding the biases of alternative accounts. Psychon Bull Rev 19:395-404. CrossRef Medline

Gibbons RD, Hedeker DR, Davis JM (1993) Estimation of effect size from a series of experiments involving paired comparisons. J Educ Behav Stat 18:271-279.

Gläscher J (2009) Visualization of group inference data in functional neuroimaging. Neuroinform 7:73-82. CrossRef

Glover GH, Li TQ, Ress D (2000) Image-based method for retrospective correction of physiological motion effects in fMRI: RETROICOR. Magn Reson Med 44:162-167. CrossRef Medline

Goffaux P, Redmond WJ, Rainville P, Marchand S (2007) Descending analgesia - when the spine echoes what the brain expects. Pain 130:137-143. CrossRef Medline

Kong J, Gollub RL, Polich G, Kirsch I, Laviolette P, Vangel M, Rosen B, Kaptchuk TJ (2008) A functional magnetic resonance imaging study on the neural mechanisms of hyperalgesic nocebo effect. J Neurosci 28 : 13354-13362. CrossRef Medline

Kong Y, Jenkinson M, Andersson J, Tracey I, Brooks JC (2012) Assessment of physiological noise modelling methods for functional imaging of the spinal cord. Neuroimage 60:1538-1549. CrossRef Medline

Kovelowski CJ, Ossipov MH, Sun H, Lai J, Malan TP, Porreca F (2000) Supraspinal cholecystokinin may drive tonic descending facilitation mechanisms to maintain neuropathic pain in the rat. Pain 87:265-273. CrossRef Medline

Koyama T, McHaffie JG, Laurienti PJ, Coghill RC (2005) The subjective experience of pain: where expectations become reality. Proc Natl Acad Sci U S A 102:12950-12955. CrossRef Medline

Levine JD, Gordon NC, Fields HL (1978) The mechanism of placebo analgesia. Lancet 312:654-657. CrossRef Medline

Light AR, Perl ER (1979) Spinal termination of functionally identified primary afferent neurons with slowly conducting myelinated fibers. J Comp Neurol 186:133-150. CrossRef Medline

Loftus GR, Masson MEJ (1994) Using confidence intervals in withinsubject designs. Psychon Bull Rev 1:476-490. CrossRef

Lorenz J, Hauck M, Paur RC, Nakamura Y, Zimmermann R, Bromm B, Engel AK (2005) Cortical correlates of false expectations during pain intensity 
judgments—a possible manifestation of placebo/nocebo cognitions. Brain Behav Immun 19:283-295. CrossRef Medline

Marshall TM, Herman DS, Largent-Milnes TM, Badghisi H, Zuber K, Holt SC, Lai J, Porreca F, Vanderah TW (2012) Activation of descending pain-facilitatory pathways from the rostral ventromedial medulla by cholecystokinin elicits release of prostaglandin- $\mathrm{E}_{2}$ in the spinal cord. Pain 153:86-94. CrossRef Medline

Millan MJ (2002) Descending control of pain. Prog Neurobiol 66:355-474. CrossRef Medline

Mogil JS, Sorge RE, LaCroix-Fralish ML, Smith SB, Fortin A, Sotocinal SG, Ritchie J, Austin JS, Schorscher-Petcu A, Melmed K, Czerminski J, Bittong RA, Mokris JB, Neubert JK, Campbell CM, Edwards RR, Campbell JN, Crawley JN, Lariviere WR, Wallace MR, et al (2011) Pain sensitivity and vasopressin analgesia are mediated by a gene-sex-environment interaction. Nat Neurosci 14:1569-1573. CrossRef Medline

Montgomery GH, Kirsch I (1996) Mechanisms of placebo pain reduction: an empirical investigation. Psychol Sci 7:174-176. CrossRef

Neubert MJ, Kincaid W, Heinricher MM (2004) Nociceptive facilitating neurons in the rostral ventromedial medulla. Pain 110:158-165. CrossRef Medline

Petrovic P (2008) Placebo analgesia and nocebo hyperalgesia-two sides of the same coin? Pain 136:5-6. CrossRef Medline

Piché M, Cohen-Adad J, Nejad MK, Perlbarg V, Xie G, Beaudoin G, Benali H, Rainville P (2009) Characterization of cardiac-related noise in fMRI of the cervical spinal cord. Magn Reson Imaging 27:300-310. CrossRef Medline

Rodriguez-Raecke R, Doganci B, Breimhorst M, Stankewitz A, Büchel C, Birklein F, May A (2010) Insular cortex activity is associated with effects of negative expectation on nociceptive long-term habituation. J Neurosci 30:11363-11368. CrossRef Medline

Scott DJ, Stohler CS, Egnatuk CM, Wang H, Koeppe RA, Zubieta JK (2008) Placebo and nocebo effects are defined by opposite opioid and dopaminergic responses. Arch Gen Psychiatry 65:220-231. CrossRef Medline

Sotgiu ML, Brambilla M, Valente M, Biella GE (2004) Contralateral input modulates the excitability of dorsal horn neurons involved in noxious signal processes. Potential role in neuronal sensitization. Somatosens Mot Res 21:211-215. CrossRef Medline

Sprenger C, Eippert F, Finsterbusch J, Bingel U, Rose M, Büchel C (2012) Attention modulates spinal cord responses to pain. Curr Biol 22:10191022. CrossRef Medline

Stroman PW, Nance PW, Ryner LN (1999) BOLD MRI of the human cervical spinal cord at 3 tesla. Magn Reson Med 42:571-576. CrossRef Medline

Summers PE, Ferraro D, Duzzi D, Lui F, Iannetti GD, Porro CA (2010) A quantitative comparison of BOLD fMRI responses to noxious and innocuous stimuli in the human spinal cord. Neuroimage 50:1408-1415. CrossRef Medline

Urban MO, Gebhart GF (1999) Supraspinal contributions to hyperalgesia. Proc Natl Acad Sci U S A 96:7687-7692. CrossRef Medline

Valet M, Sprenger T, Boecker H, Willoch F, Rummeny E, Conrad B, Erhard P, Tolle TR (2004) Distraction modulates connectivity of the cingulofrontal cortex and the midbrain during pain-an fMRI analysis. Pain 109:399-408. CrossRef Medline

Voudouris NJ, Peck CL, Coleman G (1989) Conditioned response models of placebo phenomena: further support. Pain 38:109-116. CrossRef Medline

Voudouris NJ, Peck CL, Coleman G (1990) The role of conditioning and verbal expectancy in the placebo response. Pain 43:121-128. CrossRef Medline

Wager TD, Rilling JK, Smith EE, Sokolik A, Casey KL, Davidson RJ, Kosslyn SM, Rose RM, Cohen JD (2004) Placebo-induced changes in FMRI in the anticipation and experience of pain. Science 303:1162-1167. CrossRef Medline

Wang X, Zhang J, Eberhart D, Urban R, Meda K, Solorzano C, Yamanaka H, Rice D, Basbaum AI (2013) Excitatory superficial dorsal horn interneurons are functionally heterogeneous and required for the full behavioral expression of pain and itch. Neuron 78:312-324. CrossRef Medline

Whalley B, Hyland ME, Kirsch I (2008) Consistency of the placebo effect. J Psychosom Res 64:537-541. CrossRef Medline 